\title{
Strategies for Integrating Emerging Technologies: Case Study of an Online Educational Technology Master's Program
}

\author{
Betul C. Czerkawski \\ University of Arizona, United States
}

\begin{abstract}
Emerging technologies do not necessarily facilitate or advance learning processes; teaching strategies that are used in the learning process, integration and incorporation methods do. In online instruction, research shows that "effective distance education depends on the provision of pedagogical excellence" (Bernard et al., 2004, p.413). From this perspective, a case study was conducted as a means of preliminary evaluation in a graduate program so that the effectiveness of emerging technologies and their impact on student learning could be understood. The article starts with a description of a case where emerging technologies are integrated throughout the curriculum of an online educational technology master's program. It then discusses concerns related to the integration practices and whether these practices are in line with the foundational pillars of educational technology as described by Spector (2012). Finally, a set of suggestions are proposed for those graduate programs incorporating emerging technologies in online learning on a regular basis. The analysis of this case study would benefit others in two major ways. First, faculty members can conceptualize emerging technology integration using a recent framework. Second, such a conceptualization would set the stage for deeper analysis of learning effectiveness and program evaluation.
\end{abstract}

Keywords: Technology integration; Emerging technologies; Online master's programs; Program evaluation; Learning effectiveness.

\section{Introduction}

Emerging technologies are defined as "tools, concepts, innovations, and advancements utilized in diverse educational settings to serve varied education-related purposes" (Veletsianos, 2010, p.3). Today, there are numerous emerging technologies that are free and web-based. What makes these tools valuable is not only their easy availability but also their potential to support meaningful learning, as well as increased collaboration, interaction and active participation. Stokke (2004) believes the rapid surge of emerging technologies "will not only have the potential for continuing and rampant change in higher education, but also for a radical change of the strategic and organizational logic of universities and corporate learning institutions as we know them" (p.975). In addition to this promise, "the emerging technologies can also reduce the digital divide - groups with particular learning difficulties can be assisted through access to learning activities which suit their learning styles, preference and/or learning need" (Millea, Green, \& Putland, 2005, p.3). 
From the pedagogical perspective, it is essential to recognize emerging technologies and tools as a way of enabling new types of information and messages in the learning process. "Since expression and communication are based on representations such as language and imagery, the process of learning is enhanced by broadening the types of instructional messages students and faculty can exchange" (Dede, 1996, p.5). Emerging technologies have the potential to deliver complex messages that are in line with today's complex world. These technologies also have the capacity to deliver messages that are personalized and learner-centric.

Although emerging technologies have the capacity to enhance online learning environments, many express their concern about technology integration process. For instance, Keengwe, Onchwari and Wachira (2008) think that "while access to educational technology tools has remarkably improved in most schools, there is still concern about instructional integration of computer technology to support student learning" (p.560). They emphasize the complexity of technology integration process with many factors such as teacher motivation, perceptions, and belief about learning and technology.

As more and more higher education institutions embrace online instruction (Allen \& Seaman, 2011), the emerging technologies are becoming an important part of online instruction, especially in educational technology programs, where these technologies are used, examined, and evaluated regularly. When evaluating educational technology, "typically evaluations focus on comparisons of feature checklists and costs, often narrowly defined as license fees" (Hanson \& Robson, 2003, p.2). Lesgold (2003) states that "a new approach to evaluation, research and development is needed that allows innovative ideas to be understood and evaluated in a context-grounded way" (p.39). In this study, rather than creating checklists and listing features of software, a graduate online master's program has been chosen as a case to conceptually better understand the impact of emerging technologies for learning so a more holistic and conceptual approach could be adapted for evaluation. This article reviews various emerging technologies that are used in an online master's program by the faculty members. It will also discuss concerns related to the integration practices and whether these practices are in line with the foundational pillars of educational technology as described by Spector (2012). Finally, a set of suggestions will be proposed for those graduate programs that are incorporating emerging technologies in online learning on a regular basis. It is the author's hope that using this case study, others can conceptually think about what technology effectiveness means in their online programs, and gather qualitative data to set the stage for a wider empirical study.

\section{Description of the Case: An Online Educational Technology Program}

The College where the Educational Technology degree is offered is a branch campus of a large land-grant research University that was founded for outreach border communities in various locations and campuses. Due to its location, the branch campus and the University have a high non-traditional student population (full-time employees, parents with children, stay-at-home mothers, retired military personnel, professional seeking a new career, to name a few) as well as students from minority groups (mostly Hispanic and American-Indian). The majority of the students are first generation college graduates in their families. Since the College is serving students in multiple locations on the Southern border, online formats and the interactive TV (ITV) 
system are regularly used by most faculty members and programs. Most students in this College have access to internet and computer technologies. However, taking online courses and pursuing an online graduate degree is a new experience for most of the students.

In 2008, the Educational Technology Program decided to restructure its curriculum and mode of instruction. Initially, the program was a small face-to-face program derived from a Masters' degree in Educational Psychology; consequently, there were many inconsistencies in the curriculum. Most courses lacked a syllabus, their names and brief outlines did not match their title, and their content was out-dated. There were no teaching materials or documents available to the instructors. Thus, the biggest challenge faced at the beginning was building a solid curriculum. The author aggressively started revamping and updating existing courses, creating new ones, and aligning each course with the professional standards (AECT Standards). It was ensured that the Educational Technology Program contained all the core and emerging knowledge of the field. Another important change was the mode of instruction. The curriculum of the Program was redesigned for a fully online environment, moving it from face-to-face to online.

According to Siemens and Tittenberger (2009) "early adopters of new technology often employ a grassroots approach -using resources outside of formal institutional support. This model is effective for individuals with high technical skill or an interest in innovating and reforming teaching practices" (p.15). This statement very much characterizes the situation of the aforementioned Educational Technology Program. Besides all the curricular changes, one of the highlights of this restructuring phase was integration of emerging technologies that were previously never used in the program-and not supported by the Institution or College. Some of these emerging technologies are listed in Table 1.

Table 1. Emerging Technologies Used in the Case Study

Technologies

Course/Content Management System

Web 2.0 Technologies

Synchronous Instruction Technologies

Social Networking Technologies

Productivity Technologies

\section{Tools}

Moodle, Canvas, Drupal

Blogs, Wikis, Social Bookmarking tools, Virtual Worlds (Second Life, OpenSim), Podcasts, Various educational games.

Blackboard Collaborate, Skype, Panopto

Facebook, Linkedln, Pinterest, Flickr, Twitter, Google+

Prezi, GoogleDocs, Mindmap, IHMC Cmap, VoiceThread

Dropbox 


\section{Concerns Related to Technology Integration}

While the efforts for restructuring the Master's Program may present a successful case, there are also concerns with emerging technologies. After five years of instruction in this revamped and restructured online mode, it is not clear if students learn better, or the emerging technologies really facilitate and elevate student learning. As Millea, Green and Putland (2005) put it "while the integration of emerging technology into education portends a paradigm shift - a revolutionary one according to many - in both pedagogical practice and educational philosophy, the way forward is not always clear" (p.10). It is time to look at these issues in depth and analyze whether current integration practices provide better learning experiences for the students.

Snoeyink and Ertmer (2001) discuss external and internal barriers to technology integration. According to them, external barriers are lack of equipment, unreliability of equipment, lack of technical support and other resource related issues. Internal barriers include institutional issues such as organizational culture and teacher level factors, such as beliefs about teaching and technology and openness to change. While similar discussions exist in the literature, in this case study, six foundational pillars of educational technology as described by Spector (2012) are used to gauge the integration concerns so that qualitative data could be collected before conducting a more comprehensive empirical research about learning effectiveness and program evaluation.

\section{Methodology}

The purpose of the study is to conceptually analyze an existing program's use of emerging technologies, so a more comprehensive analysis that includes both quantitative and qualitative methods could be conducted in the future. A qualitative case study design was chosen for this preliminary study because the method is well suited to learning about the experiences of an online master's program which may help shedding light on other programs that have undergone similar experiences. Case study design allows the researcher to take a close look at a problem or situation and sets aside contextual suggestions for others who are in similar situations (Yin, 1994).

Yin (1994) identified three types of case study: Exploratory, explanatory, and descriptive. This study is explanatory because it investigated a casual element, emerging technology use in a graduate program, so that overarching principles of emerging technologies could be generated in future evaluations.

The research question that was studied is: "What pedagogical concerns or challenges exist when integrating emerging technologies into an online master's program's curriculum?" In this analysis, Spector's six pillars of educational technology was used as a conceptual framework and served as the criteria for evaluation. Following sections include a brief overview of these six pillars and then responds to the questions provided by Spector for each pillar that provides a foundation for educational technology. 


\section{Foundations of Educational Technology}

Educational technology is a field of study that is informed and supported by other disciplines. According to Spector (2012) there are six major foundational areas that educational technology relies on: communication, interaction, environment, culture, instruction and learning.

Communication: While communication skills are essential to almost all other fields, educational technology heavily uses communication theories, where information is presented, received, transmitted, and processed. "Those who construct and deliver messages to support learning and performance need to think carefully about the purpose and the intended audience in order to design effective instructional messages" (Spector, 2012, p.19).

Interaction: We all learn by interacting with the instructional messages as well as other learners and instructors. In the context of online learning, interaction with the computer interface (humancomputer interaction) also plays an important role in the learning process. The interaction discipline helps educational technology by making the learning process an active and participatory action. The impact of interaction on educational technology becomes evident in the use of formative assessment as well.

Environment: A learning environment consists of physical (learning place) and psychological (learning space) and organizational context where learning takes place (Spector). Regardless of context of the environment, learning happens within a system. Therefore, educational technologists should consider a systemic approach in their efforts to integrate technology.

Culture: While culture presents a rather broad foundational pillar for educational technology, in the context of online instruction, culture refers to the varied practices of different learning communities. Online instruction provides an excellent platform and opportunity for diverse cultural communities to get together and learn from each other. In addition, diverse languages, cultural practices and habits also open up a global level of interaction among today's geographically dispersed learners.

Instruction: This foundation is simply the process of facilitating the learning. Instruction, with its many theories, models, approaches and methods, is closely related to the learning process. In the context of educational technology, instruction guides the learning process at every level, from planning to implementing, assessment to revising.

Learning: This foundational pillar refers to the very purpose of educational technology practices. As a field, educational technology tries to improve the learning, which is a complex and multilayered process. As a result of educational technology, it is expected that learners develop better understandings, experiences and expertise.

\section{Findings}

Using the foundational pillars of educational technology, Spector (2012) points out major areas of concerns with the integration of educational technologies. Using his framework, the following 
paragraphs discuss aforementioned Educational Technology Program's experiences with the emerging technologies.

\section{Communication}

Do all stakeholders fully understand and appreciate the purpose and potential of technology to be integrated? While the Educational Technology Program is fully supported and appreciated by other programs, administrators and staff members in the College, there is no indication that any of these technologies are understood by the stakeholders. Keengwe, Onchwari and Wachira (2008) state that many institutions invest in online education thinking that their long term spending costs will be lower but "this practice, does not necessarily enhance effective technology integration, but it continues to put more pressure on teachers who are reportedly not integrating technology into their courses" (p. 561). Since this situation will not change anytime soon it is extremely important to encourage risk taking instructors and reward them so educational environments would be relevant to today's learners and workplace.

Are user guides readily available and easily understood? There are a few user guides for the use of emerging technologies. The program faculty extensively uses online resources to support existing resources.

Are robust and personalized feedback mechanisms in place? "Whether a classroom is on ground or online, for the learning environment to be stimulating, reinforcing, easy to access, relevant, interactive, challenging, participatory, rewarding, and supportive, it should provide input, elicit responses, and offer assessment and feedback" (Delich, Kelly \& Mclntosh, 2008, p. 15). In an online learning environment, feedback is critical because learners are working outside of the usual classroom social environment. Some think that (Contijosh-Escontria, Burns \& Candlin, 2012) quality and constant feedback is one of the most essential factors in the success of online instruction and some others (Wieling \& Hofman, 2010; Espasa \& Barbera, 2011) argue that quality feedback has direct impact on student performance. In the aforementioned online master's program, formative assessment instruments are integrated throughout the curriculum and all instructors are careful in providing quality feedback to the students. In addition, end of course evaluations show that the program faculty members are open to any student feedback during the semester.

\section{Interaction}

Does the technology promote active learning engagement with learning materials, other learners, and teachers/trainers? Well-designed communication pathways and live interaction are important factors for the success of online students (Park, Lim, McBride, McFerrin \& Kim, 2007). While there is no complete set of evidence that shows emerging technologies promote active engagement, students are encouraged to participate in hands-on collaborative projects, and share them with the rest of the class. 
Do learners have sufficient opportunity to create their own materials and share these with others? All courses are heavily project-based and hands-on; therefore students have plenty of opportunities to create their own materials. Once the projects are completed, they are shared with the rest of the class, to comment or provide feedback.

\section{Environment}

Is the environment in which the technology will be used conducive to its use? Students have various skills in technology, so while they are all encouraged to use emerging technologies there is no mandate for their use. The learning and teaching environment is perfectly aligned with various uses of emerging technologies.

Will use of the technology draw undue attention to users or disturbs others? The answer heavily depends on which emerging technology is used and how. For instance, while Blackboard Collaborate or Skype is used, the audio issues may easily create a distraction for the students. In addition, when instructors are new to a technology, their initial discomfort can affect the students. However, these are very rare and short term issues.

Is there adequate support for ongoing use of the technology? Back in the 1990s when educational technology was new in educational environments, administrative support was extremely important. In 1996, Ritchie identified eight factors that impact technology and of these determined administrative support as the most crucial one. In 2013, the situation is quite different as most institutions support technology administratively and technically. If the online programs like ours choose to use Web 2.0 or other emerging technologies that are not supported by the institution they have to accept the fact that support should be provided internally by the department faculty.

\section{Culture}

Does the institutional culture support those willing to be among the first users of a new technology? "Successfully integrating technology does not result from isolating and focusing solely on technology issues but rather from infusing technology into the overall school culture" (Ross, McGraw \& Burdette, 2001). The institutional culture is very supportive of those technologies provided and endorsed by the University (i.e. the current CMS, the videoconferencing tools, or the new lecture capture software). If an instructor wishes to incorporate a different technology the instructor must deal with training, technical support, and troubleshooting on her own. In other words, technology choices are made by the University IT Office not by the faculty members.

Is the culture supportive of using technology to promote learning and improve instruction? While the culture might be supportive, most instructors do not know what really happens in other professors' classrooms, especially in online classrooms. K-12 level instruction might have various levels of interaction or monitoring, but at the higher education level individual professors are supported by their close colleagues or department chairs. 


\section{Learning}

Is there an adequate rationale to believe that the technology will improve learning? There is strong evidence that technology improves student learning by increasing their engagement, strengthening their research skills, allowing them to communicate better with their classmates and giving them increased control over learning (Katz, 2006; Singh, 2012). When it comes to emerging technologies, each has a strong advocate group and researchers who study their rationale for learning. However, early adopters have to assess new technologies that are not fully established and proved to be effective. In the aforementioned master's program, there is very little research conducted to measure students' reactions to emerging technologies (Czerkawski, 2011).

Will data be collected and analyzed to determine to what extent learning improves as a result of the use of the technology? To date, this has not been done systemically. The author performs regular research on emerging technologies, but a comprehensive program evaluation wasn't conducted. As a condition of their graduation, the students are required to develop an electronic portfolio which showcases their best work aligned with the AECT professional standards. These portfolios are currently the major proof of the effectiveness of emerging technologies for learning. Through the use of various emerging technologies our students show their progress in meeting program standards and outcomes.

\section{Instruction}

Is there evidence to suggest that the technology will improve the quality of instruction? In a recent study conducted by Clair and Baker (2013) researchers found that faculty members are using various technologies (e.g. Web-publishing tools and courseware management tools) for delivering educational content, however, they use these tools for only a small subset of pedagogical activities. This means that faculty members are not completely moving from simple using technology to actually integrating technology in learning environments. In addition, there is a growing body of research on emerging technologies (Berge, 2008; Veletsianos, 2007) but some of the newest ones are not accurately researched and studied yet. While there is anecdotal evidence that implies the positive impact of emerging technologies on the instruction in this particular master's program, not much has been done to understand the specific impacts of technology integration.

Will the technology be perceived as yet one more thing to be learned to do one's job or as a productivity enhancer? Students in this Program are highly motivated to learn about technology and they do not see emerging technologies as an add-on. In addition, end-of-course evaluations show that they believe that their job performance will be greatly enhanced if they have the knowledge of a wide range of technology tools.

Will data be collected and analyzed to determine the impact on instruction? Similar to impact on 'learning', impact on 'instruction' is not clear. The program needs more evidence in this regard. 


\section{Conclusions}

Teaching emerging technologies is an important part of any technology degree. While stakeholders at the higher education level are supportive of emerging technologies in general, it is not very common for programs to collect evidence on their effectiveness for learning and teaching (with the exception of institutional accreditation mandates). Probably the most common theme that emerged from the evaluation of emerging technologies using an educational technology framework is that in this online master's program there is a lack of an empirical data that supports the effectiveness of emerging technologies for learning and instruction. It is very unlikely that this particular online educational technology program is the only one facing this issue. Some other themes are:

- All stakeholders in the higher education setting do not fully understand the role of emerging technologies,

- Students are provided comprehensive tutorials or reference materials for using emerging technologies,

- Students are motivated and excited about learning emerging technologies, and faculty members are receptive to bringing more innovative emerging technologies into the learning and teaching environment,

- Learning environments are positive towards student and faculty members' use of emerging technologies,

- While institutions are supportive of faculty and students using and learning with the emerging technologies, when it comes to technology integration the users and adopters are usually on their own,

- There is not much evidence about emerging technologies and their usefulness for learning and teaching.

With regards to the effectiveness of technology use in teaching and learning, Siemens and Tittenberger (2009) point out the flaws in "measuring effectiveness" (p.51) and suggest that effectiveness studies should not focus on media or technology but pedagogical effectiveness. In other words, "practitioners should adhere to their time-tested instructional design strategies, regardless of the medium they choose" (Joy \& Garcia, 2000, as cited in Siemens \& Tittenberger, 2009, p. 51).

This paper focused on an individual educational technology program, its relatively small faculty and students and their practices with the emerging technologies. In this particular context, "greater use of emerging technology can serve as an important bridging process between the traditional role of education and the not yet clearly defined future" (Siemens \& Tittenberger, 2009, p. 53). While efforts will be made to clearly define, explain and study emerging technologies, as Siemens and Tittenberger stated, the future is still emerging and evolving, and is undefined for the most part. Moreover, the higher education institutions that will embrace the change 
symbolized by the emerging technologies will better understand and respond to the future. Finally, institutional culture greatly impacts the potential success of the technology integration process in online education. This culture means more than providing faculty training and workshops, but involving all stakeholders in the decision making process.

\section{Suggestions for Other Programs}

Emerging technologies started revolutionizing education and the dissemination of information by morphing into ubiquitous - and pervasive computing (Stokke, 2004). While this is happening faculty members who are willing to use and integrate emerging technologies into online instruction are faced with many challenges. If not addressed, their intention to bring innovation to online instruction may fail, resulting in ineffective instruction.

First, faculty members need to establish a very clear set of explanations and justifications for their use of emerging technologies. To do this, they have to answer the following questions: What technologies will be employed and when? What learning objectives and outcomes will they help achieve? What is the context of the learning? What are the strengths and weaknesses of a particular technology, and its suitability for learners? Second, there should be a good amount of information, tutorials, user manuals, and how-to videos for students to refer to for help. Third, current research on emerging technologies must be sought out, and if nothing is found, instructors should be willing to conduct their own action research to provide feedback to the existing system. In addition, faculty members should make an effort to explain and elaborate on their use of emerging technologies to their colleagues, administrators and community members, so stakeholders will have a better understanding of what can be achieved with the integration of emerging technologies. This suggestion is also related to visionary leadership within an institution. According to Millea, Green and Putland (2005) "encouraging innovative ideas and rewarding staff for sharing new practices will assist in building capacity within the education environment, enhance the system's relevance to its student body, and meet the needs of the knowledge society" (p.2). Lastly, learning and teaching strategies with the emerging technologies should be examined and studied to determine the most effective utilization of technology that fulfills learner needs and expectations. This last point may "necessitate the development of different theories, pedagogies, and approaches to teaching, learning, assessment, and organization" (Veletsianos, 2010, p.18). Stokke (2004) supports this argument and says that "the challenge today, and for the future, is to understand that harnessing the power and potential of the new information and communication technologies demands entirely new strategies and new approaches" (p. 978).

Technology integration is a complex matter and evaluation of it is even more complex. Despite the developments and research base in the educational technology field in recent years, it will be the researchers who will lead the way to justify the use of emerging technologies, and who will develop new teaching and learning strategies to effectively integrate them in online instruction. When doing this, it is essential to use theory and conceptual frameworks as the starting point and evaluate the entire program. In addition, "the evaluation of any educational technology is an iterative process that requires an interdisciplinary team to regularly review the evaluation criteria" (Kelly, 2008, p. 112). 
A literature review on the topic revealed that program evaluation efforts in educational technology are closely tied to accreditation matters in most universities (Chapman, 2006) and emerging technologies are usually evaluated around a single technology or a single course. It is the author's hope that Spector's six pillars of educational technology will serve as one of the frameworks for practitioners and help others to lay the ground for holistic program evaluations. It is unlikely that this single framework will be sufficient to deal with all the complexities of emerging technologies but it is a starting point for more comprehensive and empirical evaluations. This article also shows that a preliminary evaluation should be conducted before undertaking more compressive program evaluation efforts.

\section{References}

Allen, I. E. \& Seaman, J. (2011). Going the distance: Online education in the United States 2011. Retrieved from http://onlinelearningsurvey.com/reports/goingthedistance.pdf .Babson Survey and Research Group.

Bernard, R. B., Abrami, P.C., Lou, Y., Borokhovski, E. Wade, A., Wozney, L. et.al. (2004). How does distance education compare to classroom instruction: A meta-analysis of the empirical literature. Review of Educational Research, 74(3), 379-434. DOI: 10.3102/00346543074003379.

Berge, Z. L. (2008, May-June). Multi-user virtual environments for education and training? A critical review of Second Life. Educational Technology, XLVIII(3), 27-31.

Chapman, D. (2006, Spring). Building an evaluation plan for fully online degree programs. Online Journal of Distance Learning Administration, 9 (1). Retrieved from http://www.westga.edu/ $\sim$ distance/ojdla/spring91/chapman91.htm

Contijosh-Escontria, Burns \& Candlin (2012). Feedback in the mediation of learning in online language teacher education. In Online Language Teacher Education: TESOL perspectives. England, L. (Ed.) New York: Routledge.

Clair, S. S. \& Baker, N. C. (2013, April). Faculty use and impressions of courseware management tools; A National survey. Journal of Engineering Education. 92 (2). 123-131.

Czerkawski, B. (2011) Digital games: Are they the future of E-Learning? In Wang, H. (Ed) Interactivity in e-learning: Cases and frameworks. Hershey, PA: IGI Global.

Dede, C. (1996). Emerging technologies and distributed learning. American Journal of Distance Education, 10(2), 4-36.

Delich, P., Kelly, K. \& McIntosh, D. (2008). Emerging technologies in e-learning. In S. Hirtz \& D. G. Harper (Eds.), Education for a digital world: Advice, guidelines and effective practice from around the globe (pp. 5-22). Vancouver, British Columbia: BCcampus and Commonwealth of Learning.

Espasa, A. \& Barbera, E. (2011). Regulative feedback in an online environment in higher education: Students' perceptions and design collaborations. M. E. Paulsen (Ed.) Higher education: Teaching, internationalization and student issues (pp.177-194). New York: Nova Science. 
Hanson, P. \& Robson, R. (2003). An evaluation framework for course management technology. EDUCAUSE Centre for Applied Research, 14, 2-10.

Katz, R. N. (2006, December). The ECAR study of undergraduate students and information technology. Educause Center for Applied Research. Retrieved from http://my.hamilton.edu/ college/institutional_research/ECAR\%202006\%20exec\%20summary.pdf.

Keengwe, J., Onchwari, G. \& Wachira, P. (2008). Computer technology integration and student learning: Barriers and Promise. Journal of Science Education Technology, 17, 560-565). DOI 10.1007/s10956-008-9123-5.

Kelly, G. (2008). A collaborative process for evaluating new educational technologies. Campuswide Information Systems. 25(2), 105-113.

Lesgold, A. (2003). Detecting technology's effects in complex school environments. In G. D. Haertel \& B. Means (Eds.), Evaluating educational technology: Effective research designs for improving learning. (pp.38-74). New York: Teachers College Press.

Millea, J., Green, I. \& Putland, G. (2005, August). Emerging technologies: A framework for thinking. Australian Capital Territory Department of Education and Training. Retrieved from http://www.det.act.gov.au/_data/assets/pdf_file/0010/74485/ACT_EmTech_Report_v1_2. pdf.

Park, S., Lim, J., McBride, R., McFerrin, K. \& Kim, K. (2007). Designing effective on-line learning environments using emerging educational technologies. In R. Carlsen et al. (Eds.), Proceedings of Society for Information Technology \& Teacher Education International Conference 2007 (pp. 464-471). Chesapeake, VA: AACE.

Ritchie, D. (1996). The administrative role in the integration of technology. NASSPBulletin, 80(582), 42-52.

Ross, J. D., McGraw, T. M. \& Burdette, K. J. (2001). Toward an effective use of technology in education: A summary of research. ED 462963.

Siemens, G. \& Tittenberger, P. (2009). Handbook of emerging technologies for learning. Retrieved from: http://elearnspace.org/Articles/HETL.pdf.

Singh, N. (2012, June). Integrating technology in $21^{\text {st }}$ century classrooms. Paths towards envisioning the future. Techno LEARN, 2(1): 19-28.

Snoeyink R, Ertmer P (2001) Thrust into technology: How veteran teachers respond. Journal of Educational Technology Systems 30(1), 85-111. DOI:10.2190/YDL7-XH09-RLJ6-MTP1.

Spector, M. J. (2012). Foundations of educational technology: Integrative approaches and interdisciplinary perspectives. New York: Routledge.

Stokke, P.R. (2004). New and emerging technologies: Challenges and opportunities for learning and knowledge management in corporate- and higher education. In J. Nall \& R. Robson (Eds.), Proceedings of World Conference on E-Learning in Corporate, Government, Healthcare, and Higher Education 2004 (pp. 975-980). Chesapeake, VA: AACE.

Wieling, M. B. \& Hofman, W. H. A. (2010) The impact of online video lecture recordings and automated feedback on student performance. Computers \& Education. 54(4), 992-998. 
Veletsianos, G. (2007). Cognitive and Affective Benefits of an Animated Pedagogical Agent: Considering Contextual Relevance and Aesthetics. Journal of Educational Computing Research, 36 (4), 373-377.

Veletsianos, G. (2010). A definition of emerging technologies for education. In G. Veletsianos (Ed.), Emerging technologies in distance education. Athabasca, AB: Athabasca University Press.

Yin, R. (1994). Case study research: Design and methods (2nd ed.). Beverly Hills, CA: Sage.

Correspondence: Betul C. Czerkawski, Associate Professor and Program Coordinator, Educational Technology Program, The University of Arizona South, Tucson, Arizona, 85747, United States 